\title{
Estratégias reprodutivas e evolução da fronteira agrícola na Amazônia brasileira: um estudo qualitativo em Machadinho d'Oeste
}

\author{
Juliana Vasconcelos de Souza Barros* \\ Laura Lídia Rodríguez Wong ${ }^{\star \star}$ \\ Alisson Flávio Barbieri ${ }^{\star \star \star}$
}

Analisam-se as estratégias reprodutivas de duas coortes de mulheres que viveram seu período reprodutivo em diferentes estágios de evolução de uma região de fronteira agrícola na Amazônia brasileira. Entende-se por estratégia reprodutiva a adoção de determinado comportamento reprodutivo e contraceptivo segundo as possibilidades e adversidades oferecidas no contexto da fronteira. 0 objetivo é avaliar as mudanças nessa estratégia ao longo do processo de desenvolvimento desse tipo de fronteira. As distintas condições socioeconômicas que os estágios de desenvolvimento da fronteira oferecem tornariam as estratégias reprodutivas diferenciadas, influenciando as decisões das mulheres que viveram seu período reprodutivo nas fases iniciais ou nas mais avançadas da fronteira. Foram realizadas entrevistas semiestruturadas em Machadinho d'Oeste, Rondônia, com 60 mulheres. Os resultados apontam que, contrariamente ao referido na literatura, não haveria uma relação direta entre uso da terra e o número de filhos. 0 comportamento reprodutivo de cada coorte se relaciona mais à infraestrutura de serviços de saúde sexual e reprodutiva e às condições socioeconômicas individuais e da fronteira. Para ambos os grupos, porém, a união e a maternidade são precoces e existem elevada falha contraceptiva e alta proporção de laqueadura.

Palavras-chave: Saúde sexual e reprodutiva. Fecundidade. Fronteira agrícola. Amazônia.

\footnotetext{
${ }^{*}$ Centro de Desenvolvimento e Planejamento Regional (Cedeplar), Universidade Federal de Minas Gerais (UFMG), Belo Horizonte-MG, Brasil (julianavsbarros@gmail.com; https://orcid.org/0000-0002-1819-0813).

** Centro de Desenvolvimento e Planejamento Regional (Cedeplar), Universidade Federal de Minas Gerais (UFMG), Belo Horizonte-MG, Brasil (Iwong@cedeplar.ufmg.br; https://orcid.org/0000-0002-4041-1985).

${ }^{\star \star \star}$ Centro de Desenvolvimento e Planejamento Regional (Cedeplar), Universidade Federal de Minas Gerais (UFMG), Belo Horizonte-MG, Brasil (barbieri@cedeplar.ufmg.br; https://orcid.org/0000-0002-1133-1089).
} 


\section{Introdução}

Este artigo analisa as estratégias reprodutivas de duas coortes de mulheres - uma que viveu seu período reprodutivo nas fases iniciais da fronteira e outra que o viveu nas fases mais recentes - em uma região de fronteira agrícola da Amazônia brasileira. Entende-se por estratégia reprodutiva a adaptação do comportamento reprodutivo às diferentes adversidades e possibilidades que o contexto de fronteira apresenta à medida que evolui. 0 objetivo é compreender as motivações subjacentes à adoção de determinada estratégia reprodutiva e suas alterações em distintos estágios da fronteira agrícola.

A Amazônia tem sua ocupação contemporânea pós-1960 iniciada por meio de uma política de Estado que visava povoar e conectar econômica e politicamente a região ao restante do Brasil. Um dos pilares foi a implementação de projetos oficiais e privados de concessão de terra e assentamento de famílias para a prática da agricultura, atraindo indivíduos de todo o país. Porém, diversos fatores, além daqueles relacionados aos obstáculos naturais, limitaram seus resultados, tais como a ausência de planejamento na ocupação e na distribuição das terras, a escassez de mão de obra, capital, apoio governamental, infraestrutura e serviços, as crises epidêmicas de malária e outras doenças e o grande contingente populacional que chegou à região.

Assim, a política de ocupação logo fugiu do controle e a rede de serviços e infraestrutura se estabeleceu de forma frágil e incapaz de atender à demanda (TURCHI, 1980; HENRIQUES, 1984). Soma-se a essa complexa trama o perfil dos migrantes que se dirigiram à fronteira, cujos valores e padrões estavam associados, em sua maioria, às regiões de origem caracterizadas pela modernização agrícola e expansão urbana (TORRES, 1988; SYDENSTRICKER, 1992), além de acessarem infraestrutura e serviços que não encontraram na fronteira. Participaram, também, de mudanças demográficas importantes que se iniciaram no Centro-Sul do país, como a redução do número de filhos (SYDENSTRICKER, 1990).

Acredita-se que esses fatores moldaram diretamente o contexto social, econômico e demográfico do processo inicial de ocupação da fronteira ao longo do tempo. Consequentemente, ele impacta em diversas esferas da vida dos indivíduos, incluindo aquelas relativas às decisões e comportamentos reprodutivos. De fato, no momento inicial de abertura da fronteira, não havia uma infraestrutura sólida que permitisse às mulheres o acesso a serviços de saúde sexual e reprodutiva (SSR) (SYDENSTRICKER, 1992). Dada sua importância para definição e implementação das preferências reprodutivas e contraceptivas, as condições sociais e econômicas iniciais podem ter refletido nas decisões reprodutivas das mulheres pioneiras, dificultando a implementação ou mesmo influenciando uma reformulação das preferências reprodutivas, com base nas novas necessidades da família. 
Por sua vez, é provável que a evolução ${ }^{1}$ da fronteira tenha trazido fatores adicionais à definição do comportamento reprodutivo das novas gerações. A situação atual da região é bem diferente daquela na abertura da fronteira (BARBIERI et al., 2009), de modo que as diferentes condições em cada estágio tornariam tal comportamento específico a cada contexto.

Assim, para além da relação com o uso da terra - como apontam as teorias sobre fecundidade em regiões de fronteira no que se refere à associação entre necessidade de mão de obra familiar, tipo de uso da terra e número de filhos (MERRICK, 1978; CLAY; JOHNSON, 1992; SUTHERLAND et al., 2004; PAN; CARR, 2016) -, acredita-se que as mulheres adaptem seu comportamento reprodutivo às condições precárias da fronteira e as estratégias adotadas interagem não só com o uso da terra, mas também com o desenvolvimento, as adversidades e alternativas da região.

A hipótese é de que as mulheres que chegaram no início da fronteira possuiriam um ideal reprodutivo semelhante ao de seu local de origem, onde o processo de queda da fecundidade já havia começado (GONÇALVES et al., 2019), mas as condições econômicas e de infraestrutura foram um empecilho para implementá-lo. Isso não aconteceria com as mulheres que vivem seu período reprodutivo na fronteira atual, devido às condições de evolução da região. Além disso, haveria influência também de uma dimensão individual, relacionada à mudança nas aspirações pessoais.

Realizou-se um estudo qualitativo em um município que teve início com tal política de ocupação do Estado - Machadinho d'Oeste, em Rondônia, Brasil. Depois de mais de três décadas de existência, essa fronteira agrícola passou por diversas fases de evolução, podendo ser considerada uma fronteira praticamente consolidada (BARBIERI et al., 2016). Assim, apresenta uma janela temporal relativamente ampla de histórias para investigar a hipótese proposta.

\section{A ocupação contemporânea da fronteira agrícola e sua relação com a fecundidade}

O processo de ocupação contemporânea da fronteira agrícola na Amazônia possui relação direta com seus diferentes contextos social, econômico e demográfico, desde os anos iniciais da ocupação até o seu desdobramento atual. Esse processo, por conseguinte, impacta as decisões e o comportamento reprodutivo e contraceptivo das mulheres.

0 Projeto de Assentamento (PA) Machadinho, implementado em 1982 em Rondônia, destaca-se como o maior empreendimento de colonização no estado nesse período. Machadinho, embora representasse um progresso em relação aos demais PAs, por seu

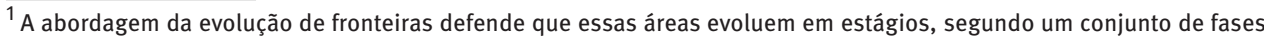
hierárquicas (HENKEL, 1982; DINIZ, 2002; SUMMERS, 2008). As fronteiras apresentam ciclos de desenvolvimento, transitando de uma economia pré-capitalista, em que há ausência de mão de obra e de um mercado de terra, para a consolidação progressiva de integração ao mercado (DINIZ, 2002; BARBIERI et al., 2014). Os estágios de evolução determinariam o desenvolvimento das características sociais e ambientais das fronteiras ao longo do tempo. Embora a abordagem seja criticada, principalmente devido a seu determinismo e linearidade (DINIZ, 2002; SUMMERS, 2008), ela é útil para organizar uma sequência temporal de evolução dos eventos complexos que se dão na fronteira e entender como as mudanças em seu contexto podem influenciar as decisões reprodutivas das mulheres em cada fase (ver BARROS, 2017).
} 
desenho e infraestrutura superiores, também vivenciou limitações no assentamento das famílias, na oferta de serviços públicos e na rede de apoio aos colonos (SYDENSTRICKER, 1990). Houve um fluxo de imigrantes para a região maior do que o planejado, fazendo com que a esperada colonização sistemática se tornasse uma ocupação desordenada, cujas consequências estruturais são visíveis até hoje.

Elevado à categoria de município em 1988, Machadinho sofreu importantes mudanças no uso do solo, ocupação dos lotes, expansão da pecuária, desenvolvimento do comércio local e das redes viárias, além de um processo de urbanização mais intenso - em comparação, por exemplo, com o lado equatoriano da Amazônia (BARBIERI et al., 2009, 2016). Essas mudanças foram acompanhadas, ainda, pelo envelhecimento da estrutura etária e diminuição no tamanho dos domicílios, menor dependência da mão de obra familiar, aumento da escolaridade e da migração rural-urbana e, mais recentemente, ampliação da importância da aposentadoria rural.

Desse modo, as decisões dos indivíduos, em todas as esferas, são reflexo de um conjunto de fatores que guardam relação não só com o núcleo domiciliar, mas também com todos os elementos desse novo contexto (SYDENSTRICKER, 1992; BECKER, 2005; BARBIERI et al., 2009). Cabe destacar que a maioria dos imigrantes de Machadinho mesclava tanto experiências rurais, por serem, em sua maior parte, camponeses que foram expropriados de suas terras pelo processo de mecanização e industrialização (SAWYER, 1983), quanto padrões de consumo de bens e serviços mais urbanizados, trazidos das áreas de origem (TORRES, 1988; SYDENSTRICKER, 1992).

$\mathrm{Na}$ realidade, o rural e o urbano estão entrelaçados na fronteira. Monte-Mór (1979, p. 6) aponta que a fronteira agrícola já nasceu urbana, como "um espaço social urbano estruturado dentro da selva amazônica”, pela própria natureza do regime de colonização. Sydentricker (1992) ressalta que, embora agrária, a fronteira não é completamente rural, mas sua essência urbana não oferece as mesmas condições de vida de uma cidade (ao menos no que diz respeito à infraestrutura de serviços e ao acesso a bens). Assim, a fronteira não pode, desde sua abertura, ser considerada um espaço rural pleno e exclusivo, pois foi constituída sobre bases urbanas que influenciam seu processo de formação e evolução (MONTE-MÓR, 2005) e, consequentemente, as diferentes estratégias adotadas pelos migrantes para se adaptar à nova vida.

Acredita-se, portanto, que a evolução e as mudanças no contexto da fronteira e nas estratégias reprodutivas estariam conectadas no tempo. Nesse sentido, a análise da fecundidade na fronteira amazônica exige compreender especificidades inexistentes em outras áreas, pois ela possui elementos peculiares que influenciam diferentemente a motivação para ter determinado número de filhos.

Em geral, essa análise é feita prioritariamente a partir do vínculo entre o tamanho da família e o uso da terra. Uma abordagem que trata dessa relação é a land-labor demand hypothesis, que sustenta que, em ambientes como as regiões de fronteira - com terra relativamente abundante, porém com limitada infraestrutura, capital e trabalho -, a mão de 
obra acaba sendo basicamente familiar, incentivando a fecundidade, visto que um maior número de membros na família significa mais pessoas para cultivar a terra (PAN et al., 2009).

Em uma visão oposta, a reverse hypothesis argumenta que são as propriedades que se adaptariam às mudanças no tamanho das famílias - ou seja, é o número de filhos de uma família que vai definir o tamanho da propriedade (CLAY; JOHNSON, 1992; CARR; PAN, 2002). Já a land-security hypothesis sustenta que o título da propriedade gera maior segurança econômica para a família, de modo que o efeito da necessidade de mão de obra e do tamanho da terra sobre a fecundidade seria anulado (CARR; PAN, 2002; SUTHERLAND et al., 2004).

Alguns autores defendem que a análise sobre o uso da terra deve considerar não o tamanho da propriedade, mas sim o estágio do ciclo de vida no qual o domicílio se encontra. Assim, a teoria do ciclo de vida do domicílio (household life cycle), inspirada nos estudos de Alexander Chayanov, sustenta que as decisões sobre uso da terra dependem da composição por idade da família, que, por sua vez, está relacionada com a disponibilidade de mão de obra para o trabalho e as necessidades de consumo do domicílio (WALKER et al., 2002; CARR et al., 2006). Isso porque o tipo de uso do solo varia conforme as mudanças na estrutura etária. Com o envelhecimento do domicílio e a saída dos filhos, a agricultura é substituída pela pecuária, que representaria segurança financeira para a família e demanda menor de mão de obra familiar, influenciando negativamente a fecundidade (SUTHERLAND et al., 2004; CARR, 2004).

Nessas abordagens, o foco não é fecundidade e preferências reprodutivas, mas sim a relação dessas com decisões sobre o uso da terra e suas consequências. Clay e Johnson (1992) ressaltam, entretanto, que uma limitação desse tipo de análise é a imprecisão sobre a natureza causal ou espúria da relação entre o número de filhos e o tamanho da propriedade: em um contexto em que a disponibilidade de instituições e serviços é precária, a ligação entre as duas variáveis pode ser intermediada também por outros fatores. Carr (2004) destaca que, mesmo que os casais desejem menos filhos, haveria elementos neutralizantes dos mecanismos inibidores da fecundidade relacionados não só à questão da terra e da mão de obra, mas também ao difícil acesso a serviços de saúde e métodos contraceptivos ou à alta mortalidade infantil, levando a nascimentos compensatórios.

Carr e Pan $(2002,2006,2016)$ apresentam, nessa linha, um conjunto de fatores associados à redução da fecundidade na Amazônia equatoriana, a partir de evidências empíricas. Existem variáveis que influenciam o uso da terra, que, por sua vez, reduziriam a fecundidade, como proximidade dos centros urbanos, presença de bens materiais, maior escolaridade e acesso à infraestrutura e à informação. A posse da terra e as decisões sobre seu uso podem tanto mediar a relação da fecundidade com determinantes próximos, como ter efeitos independentes.

Existem, ainda, questões de gênero relacionadas ao papel da mulher, como a dedicação às atividades domésticas e ao trabalho agrícola, que interferem na fecundidade (CARR; PAN, 2002). Como amplamente discutido na literatura, as relações de gênero têm grande 
influência no comportamento reprodutivo adotado e, consequentemente, no número final de filhos (BERQUÓ; CAVENAGHI, 2005; ALVES; CORRÊA, 2009; MCDONALD, 2013; CARVALHO; WONG, 2019). Em geral, a elevada desigualdade de gênero tende a promover uma fecundidade mais elevada, ao inibir o acesso a métodos contraceptivos e diminuir a autonomia feminina quanto às decisões reprodutivas, deixar a decisão sobre número de filhos somente para a mulher e impactar negativamente a saúde sexual e reprodutiva das mulheres (BERQUÓ; CAVENAGHI, 2005; CEPAL, 2010; CHACHAM et al., 2012).

Sendo predominantemente papel da mulher cuidar dos filhos e dos afazeres domésticos na sociedade em geral (ALVES; CORRÊA, 2009), na fronteira, as mulheres também são encarregadas de tarefas "leves" no trabalho na terra, como colheita, limpar o terreiro e cuidar dos animais - conciliando trabalho produtivo e doméstico com a família. Thapa et al. (1996) destacam que, nessas regiões, as mulheres assumiriam uma "carga tripla" de atividades reprodutivas, produtivas e comunitárias. Carvalho e Wong (2019) mostram, em estudo qualitativo para Machadinho, como a carga reprodutiva na fronteira está de fato mais associada à mulher. Entre os casais entrevistados, a responsabilidade pelo número de filhos era feminina, bem como o momento de tê-los e o tipo de método utilizado para evitar/espaçar nascimentos.

Apesar de poder ser entendido como autonomia feminina, essa sobrerresponsabilização feminina na fronteira parece estar mais ligada ao desequilíbrio de gênero, uma vez que imputa somente à mulher culpa em caso de gravidez não planejada, cuidado com os filhos e ausência do companheiro/pai (NOGUEIRA et al., 2018; CARVALHO; WONG, 2019). Nesse sentido, as relações de gênero entre o casal também podem impactar as estratégias reprodutivas femininas. Em contextos em que a mulher precisa assumir funções produtivas, a decisão parece ser no sentido de diminuir o número de filhos.

Sydenstricker (1990), em estudo sobre família, uso da terra e fecundidade em Machadinho d'Oeste, aponta, dentro do contexto que favorece uma alta fecundidade no processo de sua ocupação inicial, que as adversidades da fronteira tiveram reflexos significativos na fecundidade, nas escolhas reprodutivas e na realização dessas. Práticas contraceptivas trazidas da região de origem e ideais reprodutivos oriundos do contexto de queda da fecundidade no país contrastavam com serviços de saúde precários. Porém, as adversidades naturais, estruturais, socioeconômicas e de uso da terra funcionavam, em parte, como um inibidor da fecundidade (SYDENSTRICKER, 1990).

Desse modo, em seu início, as fronteiras possuíam elementos determinantes de alta fecundidade, relacionados à questão da terra e da mão de obra e ao difícil acesso a serviços de saúde e métodos contraceptivos. À medida que a fronteira evolui, ocorrem mudanças nesses elementos (como maior interdependência entre as áreas urbanas e rurais, melhorias na infraestrutura e serviços, maior escolaridade e inserção da mulher no mercado de trabalho) e, consequentemente, na dinâmica entre estratégias reprodutivas e de uso da terra, elevando o custo de oportunidade de ter um filho e modificando o padrão reprodutivo (CARR; PAN, 2002; BROWDER et al., 2008). Nota-se que o contexto da fronteira 
e o comportamento reprodutivo e contraceptivo adotado estariam conectados ao longo do tempo, de modo que as mudanças na conjuntura da fronteira impactam a forma como as mulheres decidem acerca de sua reprodução.

É importante destacar que a evolução da fronteira agrícola e as decisões reprodutivas estudadas ocorrem em um período em que a fecundidade brasileira experimentava uma transição territorialmente assíncrona. As regiões Sul e Norte (principais origem e destino do fluxo para fronteira) foram, respectivamente, a primeira e a última protagonistas da transição (GONÇALVES et al., 2019). Machadinho tem acompanhado, nas últimas décadas, o processo de transição demográfica vivenciado no país. A taxa de fecundidade total (TFT) do município, em 1991, era de 4,72 filhos por mulher, bem acima da TFT brasileira $(2,9)$ e de Rondônia $(3,5) .{ }^{3}$ As estimativas disponíveis sinalizam uma inconteste queda, com uma TFT em 2015 próxima de 1,5, menor do que a média de Rondônia $(1,8)$ (BARROS et al., 2021). Essa tendência é a verificada em outras regiões amazônicas, como, por exemplo, no delta do Rio Amazonas (SZABO et al., 2016).

Por fim, cabe ressaltar a escassez de estudos sobre a saúde sexual reprodutiva (SSR) na fronteira agrícola, visando caracterizá-la para além da fecundidade na região. No entanto, acredita-se que sua situação na região Norte possa ser utilizada como proxy, apresentando tendências semelhantes nos principais indicadores.

De maneira geral, apesar da queda nas últimas décadas, a região Norte apresenta: a maior fecundidade adolescente do país e a maior proporção de jovens com mais de um filho; a menor proporção de mulheres de 15 a 19 anos que usam métodos contraceptivos e cerca de $80 \%$ delas não queriam filhos naquele momento (CAVENAGHI, 2015); e as maiores proporções de mulheres com necessidade insatisfeita tanto para espaçar como limitar a fecundidade (TAVARES et al., 2007).

Residir na região Norte, comparativamente ao Sul e Sudeste, aumenta a probabilidade de esterilização (LAGO; LIMA, 2009), método mais usado pelas nortistas (TRINDADE et al., 2019). O preservativo também é bastante utilizado, por ser mais acessível que contraceptivos orais (CAVENAGHI, 2015; TRINDADE et al., 2019). Além disso, o Norte apresenta indicadores assistenciais menos favoráveis relativamente às outras regiões, apesar da melhoria nos últimos anos (LAGO; LIMA, 2009). Assim, em que pesem os avanços, a SSR ainda carece de atenção na região - e, acredita-se, nas áreas de fronteira, influenciando o comportamento reprodutivo.

Considerando o exposto, não é possível dissociar o contexto da fronteira das estratégias reprodutivas adotadas pelas mulheres na região. Ambos estariam conectados ao longo do tempo e a conjuntura da fronteira em cada momento impacta de forma diferenciada na decisão das mulheres acerca de sua reprodução.

\footnotetext{
2 Fonte: Atlas do Desenvolvimento Humano no Brasil.

${ }^{3}$ Fonte: IBGE, 2003. Disponível em: https://biblioteca.ibge.gov.br/index.php/biblioteca-catalogo?id=789\&view=detalhes. Acessado em: 7 abr. 2020.
} 


\section{Metodologia}

Utilizou-se uma metodologia qualitativa de coleta dos dados, ${ }^{4}$ por meio de entrevistas semiestruturadas com mulheres residentes no município de Machadinho d'Oeste. Foram entrevistadas 32 mulheres que viveram seu período reprodutivo nas fases iniciais da fronteira (até meados dos anos 1990) e 28 que o viveram nas fases mais recentes. As 60 entrevistas ${ }^{5}$ foram realizadas nas áreas urbana e rural do município. A análise das coortes cobre um período que se inicia por volta de 1985, ápice da ocupação e chegada do fluxo migratório mais intenso, até 2015.

0 recorte urbano e rural ${ }^{6}$ é necessário porque aproximadamente metade da população de Machadinho vivia em cada uma dessas áreas em 2010, sendo preciso captar a experiência desses dois grupos. 0 próprio desenho do projeto de assentamento previa uma divisão entre sede urbana e lotes rurais e, ainda hoje, os moradores enxergam essa separação, referindo-se aos lotes como "sítio" e "roça” e ao núcleo urbano como "a rua”, "o Machadinho". Soma-se, ainda, o fato de o acesso a determinados serviços, o contato com diferentes pessoas e ideias e, ainda, a relação com a terra serem bastante distintos entre os dois núcleos e dentro do próprio rural, dado que ele também é bastante diversificado. Existem lotes localizados bem próximos da área urbana e outros sítios mais distantes, o que certamente influencia na definição das estratégias reprodutivas.

O Quadro 1 apresenta o perfil das entrevistadas, segundo características socioeconômicas e indicadores do comportamento reprodutivo selecionados.

Foram elaborados quatro roteiros de entrevistas semiestruturados, com perguntas similares, porém adaptadas às especificidades dos grupos considerados. Indagou-se sobre características sociodemográficas das entrevistadas, mudança para fronteira, trabalho na terra e infraestrutura de serviços em Machadinho, além de questões sobre a fecundidade, preferências reprodutivas, contracepção, acesso a serviços de saúde, pré-natal e parto e relação entre fecundidade e uso da terra.

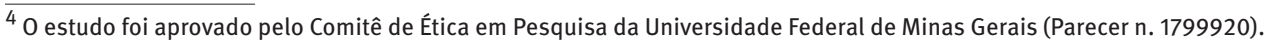
As entrevistadas assinaram um Termo de Consentimento Livre e Esclarecido, declarando concordância em participar voluntariamente da pesquisa e o conhecimento dos objetivos do estudo. 0 trabalho de campo foi realizado com o apoio do Projeto CRN 3036 LUCIA - Land Use, Climate and Infections in Western Amazonia, financiado pelo Inter-American Institute (IAI) entre 2013 e 2019.

${ }^{5}$ As entrevistas individuais, com duração média de 40 minutos, foram realizadas, gravadas e analisadas pela primeira autora deste artigo. A análise foi feita pela identificação e codificação a posteriori dos principais temas e padrões nas respostas dadas, seguindo a configuração do roteiro de entrevistas. Os nomes citados são fictícios.

${ }^{6}$ Ressalta-se que o tênue limite entre essas duas áreas requer cautela na dicotomização rural-urbano. Em que pese o fato de a fronteira "nascer urbanizada" e o tecido urbano se estender para além das cidades, alcançando o meio agrário, optou-se por denominar de rural a região de Machadinho onde se tem uma elevada concentração de sítios e lotes destinados à agricultura e pecuária (distribuídos aos parceleiros na época da colonização) e de urbano a região da cidade onde está a sede da prefeitura, o comércio e a estrutura de serviços. Essa nomenclatura é utilizada para efeitos de simplificação textual, marcando a distribuição espacial diferenciada das mulheres, sem desconsiderar, no entanto, as peculiaridades do rural na fronteira.
} 


\section{QUADRO 1}

Características selecionadas das mulheres entrevistadas em Machadinho d’Oeste, por estágio de desenvolvimento da fronteira em que viveram seu período reprodutivo

\begin{tabular}{|c|c|c|}
\hline \multirow{2}{*}{ Características } & \multicolumn{2}{|c|}{ Momento em que viveram seu período reprodutivo } \\
\hline & Estágios iniciais & Estágios mais recentes \\
\hline \multicolumn{3}{|l|}{ Residência } \\
\hline Rural & 20 & 15 \\
\hline Urbana & 12 & 13 \\
\hline Idade média (em anos) & 49,3 & 25,6 \\
\hline $\begin{array}{l}\text { Tempo médio de residência na } \\
\text { fronteira (em anos) }\end{array}$ & 24 & $\begin{array}{l}\text { Desde a infância/início da } \\
\text { adolescência }\end{array}$ \\
\hline Principais locais de origem & $\begin{array}{l}\text { Regiões Sul e Sudeste, } \\
\text { especialmente Paraná }\end{array}$ & $\begin{array}{l}\text { Região Norte, maior parte nasceu } \\
\text { em Rondônia }\end{array}$ \\
\hline Escolaridade & $\begin{array}{l}\text { Analfabetas ou ensino fundamental } \\
\text { incompleto }\end{array}$ & Ensino médio e superior \\
\hline Religião & Católica e evangélica & Maioria evangélica \\
\hline Estado civil & $\begin{array}{l}27 \text { casadas ( } 3 \text { informalmente e } \\
2 \text { em segunda união) } \\
2 \text { divorciadas } \\
2 \text { solteiras } \\
1 \text { viúva }\end{array}$ & $\begin{array}{l}20 \text { casadas (6 informalmente e } \\
3 \text { em segunda união) } \\
8 \text { solteiras ( } 3 \text { já haviam sido } \\
\text { casadas informalmente, } 5 \text { nunca } \\
\text { haviam se unido) }\end{array}$ \\
\hline $\begin{array}{l}\text { Idade média à primeira união } \\
\text { (em anos) }\end{array}$ & 18,3 & 17,8 \\
\hline $\begin{array}{l}\text { Idade média ao primeiro filho } \\
\text { (em anos) }\end{array}$ & $\begin{array}{l}18,9 \text { (mínimo } 14 \text { e máximo } 29 \\
\text { anos) }\end{array}$ & $\begin{array}{l}\text { 19,4 (mínimo } 14 \text { e máximo } \\
23 \text { anos) } \\
9 \text { não tinham filho }\end{array}$ \\
\hline Número médio de filhos & 3,4 & 2,1 \\
\hline Métodos contraceptivos utilizados & $\begin{array}{l}23 \text { fizeram laqueadura (7 utilizaram } \\
\text { apenas esse método) } \\
\text { Uso anterior de pílula e coito } \\
\text { interrompido } \\
1 \text { nunca utilizou contracepção }\end{array}$ & $\begin{array}{l}11 \text { utilizavam pílula } \\
8 \text { fizeram laqueadura } \\
2 \text { utilizavam injeção } \\
3 \text { usavam preservativo } \\
4 \text { não praticavam contracepção }\end{array}$ \\
\hline
\end{tabular}

Fonte: Elaboração dos autores.

As entrevistadas foram selecionadas por conveniência, sendo a amostra não representativa da população de Machadinho. Entretanto, adotou-se como critério entrevistar mulheres, quando possível, de diferentes condições econômicas, níveis de escolaridade, idades, estado conjugal e distribuição espacial, visando captar maior heterogeneidade de respostas. A abordagem às potenciais participantes nas áreas rurais foi feita diretamente nas residências, enquanto na área urbana a estratégia foi abordá-las nas ruas, praça e local de trabalho ou pedir indicações de quem pudesse participar.

\section{Resultados}

Mulheres que viveram seu período reprodutivo nos estágios iniciais de evolução da fronteira

As primeiras mulheres que chegaram à fronteira vieram, em sua maioria, de regiões que já haviam iniciado seu processo de industrialização e urbanização. Fugindo, muitas vezes, da expropriação do campo e de tentativas frustradas de viver na cidade, elas descrevem as 
condições adversas que encontraram em Machadinho, demandando grande esforço para se adaptarem à nova realidade.

Um sofrimento. Todo mundo foi embora. Todo mundo não aguentou. O pessoal: "Vamos embora. Aqui tu vai morrer, uma onça vai te comer, você vai morrer de malária". Eu: "Ô, gente, se eu correr o bicho come, se eu ficar o bicho pega, então vamos ficar aqui mesmo. Porque nós não temos aonde ir, nós temos que viver por Deus, porque eu não tenho condições". (Adélia, 55 anos, área rural)

A falta de infraestrutura e serviços e a incidência de doenças como a malária dificultaram muito o processo de adaptação. Ao chegarem, os assentados tinham apenas seu pedaço de terra, ainda coberto pela mata nativa, sem energia, sem água. Precisavam plantar, esperar dar frutos, construir um local para morar; todos sem recursos materiais e financeiros, sem apoio dos órgãos responsáveis.

Comecemos do nada. Porque tinha que abrir, né? Como é que você vai plantar? Nós dois sofrendo aí, em tempo de derrubar o mato. Plantemos arroz e não deu nada. [...] Depois, eu e ele plantando capim no enxadão. Porque o café, você sabe, começa a produzir com três anos. [...] Meu marido trabalhava por dia [na terra de outras pessoas] para comprar as coisas para comer, porque não tinha. Até o café começar a produzir. (Heloísa, 52 anos, área rural)

Eu cheguei em Machadinho não tinha nada, nada. [...] Não tinha Correio, não tinha Polícia, não tinha delegacia, não tinha telefone, não tinha banco. Então, era assim, [...] você andava 150 quilômetros de estrada de chão para chegar no banco, para poder pegar um telefone para ligar para alguém. Tinha um hospital. Aí tinha o médico e umas camas. Só. E malária. Quando era mais sério, se aguentasse chegar até lá [em outra cidade], chegava, se não, morria. (Glória, 46 anos, área urbana)

Em geral, a mudança para Machadinho ocorria em família. A maioria das mulheres foi seguindo o sonho do companheiro, junto com o(s) filho(s): “Eu falei para ele: 'Meu pai, mas quando a gente casa a gente tem que acompanhar o marido, né? Se ele tá indo, eu tenho que ir atrás"' (Ester, 59 anos, área rural). Isso tornava ainda mais difícil a adaptação no novo contexto, pois nem sempre era um desejo delas, mas, por estarem casadas, seguiram a decisão do cônjuge.

Soma-se a esse complexo cenário (experiências pregressas nas áreas urbana e rural, perfil do migrante e essas novas condições experimentadas na fronteira) o pouco conhecimento dessas mulheres sobre reprodução e contracepção. De maneira geral, se casaram muito jovens, sem nenhuma experiência sexual e contraceptiva. Engravidaram logo após se unirem e com intervalo curto entre os filhos: "Naquela época, ninguém nem sabia como é que tinha, se você casava para ter filho. Não sabia desse trem não" (Magda, 64 anos, área rural).

Somente após o casamento e os primeiros filhos, elas começam a pensar sobre o número de filhos que desejam, a partir das vivências que tiveram - o sofrimento da mãe tendo que cuidar de muitos filhos, as restrições econômicas e materiais e as dificuldades 
na fronteira. Ainda que não explícito numericamente, em geral, o número desejado de filhos era pequeno.

Fiquei tendo seis. Passou até um pouco mais da minha conta. Se eu deixasse, aí eu ia ficar que nem a minha mãe, que teve quinze filhos. Porque se eu arrumasse mais, eu achava que não ia ter condições, assim, de tratar eles melhor. E eles menos, a gente tem condições de tratar "mais melhor". (Geralda, 66 anos, área rural)

Nesse sentido, as condições difíceis de vida influenciavam a quantidade desejada de filhos. A implementação dessas preferências, no entanto, esbarrava na falta de conhecimento e de acesso a métodos contraceptivos. Para algumas mulheres, a descoberta de que era possível espaçar os nascimentos ou não ter mais filhos surge anos após a união e os primeiros filhos. A falta de conhecimento sobre métodos culmina em um uso tardio, após já terem tido pelo menos uma gravidez não planejada, e geralmente instruídas por alguma amiga ou familiar após sucessivos nascimentos.

Eu não pensava que eu ia ter tanto filho assim logo que eu casei, né? E, quando pensava que não, estava grávida... Até minha cunhada: "Você tem que se cuidar mais". (Ester, 59 anos, área rural)

Naquele tempo, eu nem sabia de comprimido, de camisinha, nada não. Devia ter. Eu não comprava nada dessas coisas não, só aquelas coisas que não tinha mesmo no lote. [...] No primeiro dia [após o casamento] já engravidei. Depois eu falei: "Agora tá feio, porque todo ano um filho, uma pobreza danada". Aí deu uma pausa. Eu fui parece que ficando mais esperta. (Jussara, 63 anos, área urbana)

A pílula aparece como o principal método utilizado por essas mulheres; no entanto, o uso inadequado e as dificuldades de acesso prejudicam essa prática. Nesse sentido, o coito interrompido e, sobretudo, a laqueadura surgem como métodos alternativos. É dizer, as escolhas reprodutivas e contraceptivas são condicionadas e limitadas pelo contexto em que estão inseridas, especialmente quanto às restrições de toda ordem impostas pela fronteira. Suas preferências e comportamento reprodutivo são, assim, pautados nas suas condições estruturais e experiências de vida antes e na fronteira.

Tomei comprimido. Eu acho que a gente esquece, engravidei do último menino tomando comprimido. (Nilda, 54 anos, área rural)

Não [tinha método]. Era só tirando fora mesmo o trem. (Jussara, 63 anos, área urbana)

Os resultados apontam que o principal determinante do comportamento reprodutivo dessas mulheres são as dificuldades da fronteira. Ainda que tenham vivenciado ideais reprodutivos de poucos filhos em seu local de origem, foram as condições de vida experimentadas na fronteira que reforçaram a preferência por uma baixa fecundidade:

Eu achava bonito [ter muitos filhos]. Nós queria ter pelo menos uns cinco, seis filhos, mas daí a situação tava feia. Não tinha dinheiro, não tinha nada. Daí eu fiquei assustada: "ter mais filho nessa vida não dá. Não tem nem onde que por o menino. Nessa pobreza não dá". (Heloísa, 52 anos, área rural) 
É [questão] financeira, porque você arruma filho sendo que não pode dar a eles o que pode, então é melhor parar mesmo. É muito sofrimento. (Sandra, 45 anos, área rural)

Eu achava que dois tava bom. Por todas essas coisas, sítio, correria, e a gente fraco toda vida, então eu não ia querer mais. (Virgínia, 53 anos, área urbana)

No entanto, a ausência de serviços de SSR, as dificuldades de acesso aos métodos, a situação financeira e a falta de conhecimento das mulheres limitavam a implementação dos seus ideais reprodutivos: “Depois, daí, já tinha esses comprimidinhos que a gente tomava para não engravidar. Mas era difícil para a gente comprar, era caro. A gente não ganhava, era comprado" (Edith, 59 anos, área rural).

Até mesmo o acompanhamento pré-natal e o parto eram dificultados pelas condições da fronteira. De maneira geral, as mulheres não faziam muitas consultas, tanto pela falta de conhecimento e acesso como pela infraestrutura e qualidade da assistência médica.

Naquele tempo, nem energia não tinha no hospital, daí o enfermeiro falava assim: "A senhora dá jeito de criar esse filho de dia, porque de noite não tem luz". Daí esse eu sofri, porque ele cresceu quatro quilos, e passou da hora dele nascer. Menina, ele nasceu pretinho. Fiquei três dias sofrendo dor no hospital. (Edith, 59 anos, área rural)

Morreu muita criança, muitas mulheres, porque não tinha [assistência]... Então, às vezes, as pessoas não faziam o pré-natal, não passavam pelo médico e, por ser carente demais, não eram bem atendidas. Às vezes, a mulher chegava para ganhar neném, aí o doutor via que não tinha dilatado nem nada, deixava, "você não vai ganhar hoje não". Aí ficava assim, dois, três dias esperando, ou a criança morria, morriam os dois, ou morria a mãe. (Kelly, 37 anos, área urbana)

Todo esse cenário fez com que muitas optassem por um método contraceptivo definitivo. A laqueadura surge, então, como reflexo das dificuldades de se implementar as preferências reprodutivas e das circunstâncias enfrentadas, quase sempre devido às restrições materiais vividas na fronteira. É a única solução vista por essas mulheres para evitar mais filhos não planejados.

Tinha tempo que a situação ficava meio difícil, não tinha dinheiro nem para comprar a pílula, ai passava dois meses, três meses sem comprar e ficava grávida. Fui operada para poder parar. Pobre, ainda arrumar filho, é a maior tristeza do mundo. Porque você arrumar filho sendo que não pode dar a eles, então é melhor parar mesmo. (Sandra, 45 anos, área rural).

Os companheiros das mulheres, em geral, parecem ter pouca participação nas decisões reprodutivas, ficando mais a cargo da mulher decidir a quantidade, especialmente quando não mais ter filhos. 0 marido normalmente opina apenas para barganhar mais um filho de sexo oposto aos que eles já têm, mas a decisão final parece ser sempre da mulher.

Não, ele não falava para não ter mais, ele achou que tava bom esse tanto. Ele também nunca me pediu. Acho que se fosse para ter mais, podia. Ele não ia incomodar não. (Conceição, 51 anos, área rural)

Ele queria que eu esperasse vim uma menina mulher, porque só tem homem. Mas eu falei: “Não vou querer mais não”. (Sandra, 45 anos, área rural) 
Ele [marido] não pensava em nada não, o que vinha tava valendo. (Virgínia, 53 anos, área urbana)

A decisão pela laqueadura também é, quase sempre, tomada pela própria mulher. Ainda que o companheiro demonstre ser contra, prevalece a escolha da mulher, de modo que as estratégias reprodutivas são sempre traçadas por elas.

(Entrevistadora: O seu marido não se importou da senhora fazer não?) Não. Ele falou: "Você que sabe. Se você quiser fazer, você faz", aí eu fiz. (Ester, 59 anos, área rural)

Quando eu queria operar, eu queria operar até do meu menino, ele não quis. Tipo assim, ele sempre quis ter mais, eu falei: “Não, não quero. Não é você que vai ter". (Marisa, 43 anos, área urbana)

A falta de informação sobre concepção e contracepção e o número excessivo de filhos relacionam-se, em grande medida, ao papel colocado para a mulher. Elas não tiveram muitas alternativas ou possibilidades de trabalho e estudo e o ideal de vida da maioria acabava sendo casar e ter filhos, tal qual suas mães e avós. Não tiveram oportunidade de estudar nem se inserir em outras ocupações que não o trabalho no sítio.

Antigamente, a gente pensava assim: estava na casa do pai e da mãe? Então vou casar, ter minha casa, ter meu marido, e vou mudar de vida. (Denise, 54 anos, área rural)

Ah, na minha época de juventude a gente era assim, você pensava em arrumar um namorado e casar. Não tinha muito sonho, tipo, sonhar que vou estudar, que eu vou arrumar um emprego bom... Não! Sonhava em arrumar um namorado e casar. (Glória, 46 anos, área urbana)

As pioneiras, inclusive, acreditam que seus sonhos e perspectivas, quando jovens, eram diferentes do que os das gerações mais novas. 0 modo como foram criadas, o contexto que viveram na fronteira, a falta de estudo e de conhecimento sobre a vida fizeram com que suas expectativas fossem limitadas à realidade que vivenciaram, restando apenas cuidar da família e da terra - mesmo entre aquelas vindas da área urbana, o nível de escolaridade era baixo e pouquíssimas trabalhavam fora de casa.

Eu tenho as minhas noras, eu tiro por elas: elas agora pensa em estudar. Igual a minha nora mesmo ali, ela tem vontade assim, de arrumar emprego, de trabaiá. A outra, em Machadinho, é empregada também, trabaia. Porque antes a gente morava no sítio, a gente não tinha outra alternativa. Era só sítio, trabaiava no sítio mesmo e pronto, não tem outra alternativa. Porque os pais não deixava os filhos ir para rua de jeito nenhum antigamente. Hoje em dia, a maioria das moças, termina o estudo e já vai para a rua. (Sandra, 45 anos, área rural)

Minha filha, ela tá com 18 anos e ela já tá na faculdade. Se tivesse acontecido isso comigo, eu teria uma vida bem melhor, eu tinha tido uma vida melhor. (Graça, 45 anos, área urbana)

Quando perguntadas se a quantidade de filhos tidos estava relacionada ao trabalho na terra, as entrevistadas são unânimes em descartar tal relação. Ou seja, diferentemente do que apontam as teorias de fecundidade na fronteira, não haveria, no grupo de mulheres pioneiras do local estudado, uma relação direta entre produção e reprodução - no sentido de ter filhos para trabalho, mão de obra e uso da terra. A baixa produtividade inicial, o futuro 
incerto na fronteira recém-chegada, as dificuldades materiais e financeiras, a necessidade de trabalhar em terra de outras pessoas e a precária infraestrutura do PA teriam atuado, na realidade, como fatores limitantes da intenção de se ter (mais) filhos.

Ajudar não, porque serviço de terra é muito difícil, não é todo filho que quer trabalhar na terra. E dá trabalho mexer, manter todo mundo. Acho que é pior [ter muitos filhos]. (Sandra, 45 anos, área rural)

Não ajudou muito. Porque quando eu vim, nós morava no sítio, mas em terras dos outros. Aí, só ele [marido] que trabalhava, porque era terra dos outros, não podia fazer nada. Aí, quando nós tivemos nossas terras, os filhos já estavam grandes. (Geralda, 66 anos, área rural)

Eu acho que era mais falta de acesso [a métodos contraceptivos], de elas terem alguma orientação. Eu acho que para trabalhar não. Eu acho que não influenciava não. (Cristina, 40 anos, área urbana)

Assim, as estratégias reprodutivas parecem ter sido definidas mais pelas condições materiais de vida na fronteira do que o uso da terra. Mais especificamente, estão relacionadas à compatibilização entre o número de filhos (especialmente os fora de idade laboral e, portanto, apenas consumidores nos domicílios) e às necessidades de produção e de subsistência domiciliar. Embora os filhos constituíssem uma mão de obra importante, sua ajuda dependia da idade e do sexo das crianças, da posse da terra e, ainda, da conciliação do trabalho feminino na terra com a quantidade de filhos para cuidar.

O caso delas ser menina né, elas trabalharam, mas não foi muito não. Porque menina não é que nem homem, no serviço assim, de roça. Elas trabalhavam assim, para colher um café, cortar um arroz. Serviço leve. (Conceição, 51 anos, área rural)

Só o mais véio que ajudou assim, ele trabalhou dos nove anos. Levei ele pra roça para roçar, para carpir. Dos nove anos até os quatorze anos, ele... o [do meio] carpiu um pouquinho só também e não quis mais. Também eu não forcei. Tudo pequeno, eles tinham que estudar também. Mas o caçula nunca trabalhou. Mas não gosta de roça de jeito nenhum. (Heloísa, 52 anos, área rural)

Depois que cresceram um pouquinho. Porque pequenininho era só eu mesmo que panhava. [Deixava as crianças] em casa mesmo. O barraquinho é pertinho, é no meio do café, daí eu ia em casa e olhava eles. O meu menino mais velho cuidava deles para mim. (Tereza, 48 anos, área rural).

Mulheres que viveram a maior parte do seu período reprodutivo nos estágios mais avançados de evolução da fronteira

As mulheres que viveram seu período reprodutivo nas fases mais atuais da fronteira nasceram, em sua maioria, em cidades próximas ou em Machadinho. Apesar de terem passado parte da infância no contexto das fases iniciais da região, experimentaram maior urbanização, crescimento do centro comercial, maior facilidade de locomoção e comunicação e aumento de serviços públicos, especialmente de saúde. Ainda que existam pontos a aprimorar, acreditam que a infraestrutura do município tem melhorado. 
[Hospital] só na cidade. Depois de muitos anos que veio abrir o postinho. Depois de uns três anos que nós estávamos aqui tinha umas estradas boas, o hospital funcionava bem. [...] Não tinha energia, era lamparina e poço. Puxava água no braço tá, para tudo. A gente veio da cidade, batia na máquina, chegou aqui, lavava na mão. (Carolina, 27 anos, área urbana)

Mudanças no uso da terra e nas condições do solo também são percebidas pelas entrevistadas: "Na minha infância, lá por volta do ano 96 até 2003, mais ou menos, plantava milho, arroz, feijão, tinha as lavouras de café. [...] Acabou. Tinha mais no final só pasto e café. Hoje, por sinal, é só pasto" (Larissa, 21 anos, área rural).

De forma geral, a vivência da coorte mais nova na fronteira é diferente das pioneiras. São mulheres mais escolarizadas e possuem maior contato com outros valores e ideais. A busca por melhores educação e emprego é vista como um valor importante: “Eu acho que hoje em dia as mulheres têm mais convicção, mais chances de arrumar o futuro, de trabalhar, construir um futuro melhor do que antigamente [...] poder estudar, trabalhar e ter um futuro. Tratar a mulher de igual para igual é melhor, né?”(Clarice, 21 anos, área rural).

Ao contrário da coorte mais velha, elas possuem mais oportunidades de estudo e trabalho fora do sítio e enxergam que podem ter outro destino, ampliando seus horizontes de planos como não foi possível para a outra geração de mulheres. As mudanças culturais e no papel da mulher na sociedade teriam, em sua visão, grande peso nas novas escolhas e perspectivas femininas a cada geração. Não que elas não desejem casar e ter filhos, mas esse não é mais um ideal de vida; ao contrário, isso ocorrerá apenas depois de estudarem e alcançarem um futuro mais promissor - mesmo que nem sempre seja possível realizar.

Hoje já mudou, hoje a mulher já pensa em outras coisas, já busca estudar, já busca trabalhar, para a pessoa financeiramente né, independente. As mulheres antigamente não tinham essa visão. (Larissa, 21 anos, área rural)

Eu creio que a maioria das mulheres, independente da sua vida, da sua carreira, elas planejam muito bem a questão de ter filho. [...] Eu acho que os planos delas é estudar, trabalhar. Já não é mais tanto casar. Hoje elas tão querendo mais é estudar, curtir a vida. Porque com filho ela não vai poder mais trabalhar, dependendo não tem uma creche, não tem quem cuida, aí a vida dela vai se tornar um pesadelo. Então, hoje eu acho assim, que as mulheres já pensa tudo isso. (Mariana, 32 anos, área rural)

Assim, elas têm mais expectativas e possibilidades em relação ao seu futuro, além de constituir família, quando comparadas à outra coorte. E são esses novos valores que influenciam suas preferências por um menor número de filhos nos estágios mais avançados da fronteira. Elas parecem ter definição mais clara, mesmo antes de se casar, de qual seria o número ideal de filhos que querem e o momento de tê-los, considerando sua situação atual, contexto socioeconômico, planos individuais e exigências para se criar um filho.

Agora não é uma vantagem, porque, primeiro, a gente está morando aqui [com os pais]. Depois que tiver estabilizado, cada um tiver profissionalmente mais estabilizado, sim. Também porque as coisas não estão fáceis hoje em dia. Eu penso assim, ter mais filhos, primeiro tem que pensar na qualidade de vida que essas crianças vão ter. Colocar uma 
criança no mundo e depois não ter condições de dar o que a criança precisa, é complicado. (Suzana, 25 anos, área rural)

Eu pretendo casar e ter filhos, mas primeiro eu quero terminar minha faculdade. (Isabela, 18 anos, área urbana)

Ao que parece, essas estratégias são definidas mesmo antes do casamento e do primeiro filho e são pouco modificadas ao longo do tempo: "Lá em casa a gente foi família grande, minha mãe teve seis filhos, aí eu via muita dificuldade. Era muito difícil criar filho, aí eu já pensava na minha cabeça antes 'vou ter só dois filhos só e pronto'” (Betânia, 33 anos, área urbana).

Em geral, a coorte mais jovem é mais bem-sucedida em realizar essa preferência, comparada às mulheres do início da fronteira; conseguem um intervalo de tempo maior entre o casamento e o primeiro nascimento e entre os nascimentos. Assim, há menor proporção de filhos não planejados.

Eu demorei quatro anos depois de casar para poder ter ele. Assim, eu tava planejando preparar primeiro uma casa, porque eu fui morar logo com a minha sogra. Aí eu demorei quatro anos para ter ele e acho que mais quatro para a outra, a menina. Já era tudo assim, planejado. (Mariana, 32 anos, área rural)

Eu queria mesmo. Ela foi planejada. Parei [de tomar pílula] para poder engravidar. (Melissa, 25 anos, área urbana)

Há elevada proporção de uso de métodos contraceptivos, inclusive pelas mulheres solteiras, e maior variedade (ver Quadro 1). Elas conseguem espaçar os nascimentos e evitá-los mesmo não usando métodos definitivos para tal.

Você não estando operada, tem outras formas de você prevenir. Eu conheço pessoas aí que tem 20 anos que se previne, nunca engravidou. Porque o dia de amanhã a gente não sabe, parou, pronto. Se você laqueou não tem mais conserto, né? (Melissa, 25 anos, área urbana)

Mesmo sabendo ser possível evitar filhos sem uso de métodos definitivos, a laqueadura ainda é bastante difundida nessa coorte. Mesmo jovens, muitas optam por esse procedimento para não terem mais filhos, ou já planejam realizar a cirurgia futuramente. Mas, diferentemente das mulheres mais velhas, a opção pela laqueadura ocorre para se evitar filhos não planejados antes que eles ocorram. É como se elas a fizessem preventivamente, como resume Carla, 27 anos, área urbana: “Eu tenho vontade de fazer a laqueadura. Já facilita. Eu quero encerrar mesmo, não correr o risco [de ter mais um filho]".

Também entre essas entrevistadas, prevalece a decisão da mulher acerca do número de filhos, apesar de parecer haver uma interação um pouco maior entre o casal sobre o assunto. 0 marido normalmente opina no sentido de querer mais um filho, em geral do sexo oposto ao já tido. Eles também têm pouca influência na escolha do método contraceptivo utilizado, incluindo a laqueadura. Também entre esse grupo, portanto, as estratégias reprodutivas são responsabilidade majoritariamente da mulher. 
Ele nunca foi, assim, daqueles maridos de cobrar filho não. Teve mais por influência minha mesmo. Ele não faz questão não. Se eu tivesse só um, para ele tava bom demais. (Mariana, 32 anos, área rural)

Ele [marido] queria ter mais um. Eu falei: "Não. Nós temos um carro e o carro é cinco lugar”. Nós somos em cinco. (Fernanda, 30 anos, área urbana)

Ele [marido] pensa. Ele quer ter outro filho. Ele fala em três. Mas três não, dois tá bom. Dois tá bom. (Melissa, 25 anos, área urbana)

A ausência de condições mais favoráveis na fronteira parece afetar menos a realização do ideal de fecundidade do que antigamente. Talvez o maior contato com outras ideias e possibilidades de um futuro diferente, além de apenas filhos e casamento, somado ao maior conhecimento e uso de métodos, tenha maior peso nas estratégias adotadas.

Por enquanto só se formar, arrumar um bom emprego e tá bom demais. Casamento, filho, tá fora. Esse não é meus planos por enquanto. Quero arrumar um emprego bão, estabelecer mais a vida. (Clarice, 21 anos, área rural)

Nesse sentido, o comportamento dessas mulheres se assemelha mais ao da não fronteira do que ao das mulheres pioneiras. Isso não significa, no entanto, que a realidade atual da fronteira não tenha influência nas decisões reprodutivas e na fecundidade das jovens. Eventos como casamento e nascimento dos filhos, nos casos estudados (ver Quadro 1), ocorrem em idades mais jovens do que o observado no Brasil. ${ }^{7}$ Isso relaciona-se ao peso que a realidade da fronteira e as condições de vida ainda têm, para algumas mulheres, na concretização das preferências e estratégias escolhidas, mesmo que em menor medida que no passado.

Eu saí de casa até mais cedo, por causa que eu tinha vontade de ter as coisas. Como o meu pai não deixava nem a minha mãe trabalhar, ela sofreu, eu sofri. Eu comecei a trabalhar com 12 anos de empregada doméstica, para comprar as coisas. Por isso eu ponhei na minha cabeça desde cedo, já que eu não vou estudar, eu falei: “O dia que Deus preparar, que eu achar uma pessoa que seja boa, eu vou me casar logo de uma vez para parar de sofrer". Meu marido tinha 19, na época eu tinha 16, eram duas crianças [...] Como eu não estudei, a opção é casar, formar família e sossegar. Ou casa ou estuda, um dos dois, senão você vai virar o que? Nada. (Mariana, 32 anos, área rural)

Eu, quando era jovem, gostava muito de dançar. Eu tinh a muita vontade de ser dançarina profissional. Mas aqui, Machadinho é muito devagar, aqui não tem nada para fazer, não tem uma escola de dança. Então isso é sonho de adolescência que acaba ficando para trás. (Carla, 27 anos, área urbana)

Isso se reflete, ainda, em uma proporção significativa de nascimentos não planejados e falha contraceptiva, apesar do conhecimento e o uso de métodos. Assim, nem sempre a implementação das preferências reprodutivas ocorre de maneira perfeita, não obstante

\footnotetext{
7 Nacionalmente, a idade média feminina à primeira união, em 2010, foi de 23 anos. Fonte: Grupo de Foz. Métodos demográficos: uma visão desde os países de língua portuguesa. Ed. Abep - no prelo.
} 
o acesso e conhecimento. Há uma mescla entre filhos planejados e não planejados, independentemente da ordem de nascimento.

[Primeira filha] Eu queria. Eu tomava remédio naquela época, eu parei para engravidar. Essa aqui [segunda filha] eu engravidei tomando remédio. Dessa aqui [terceira filha] também. (Cíntia, 29 anos, área rural)

Usava camisinha, aí aconteceu ela. Foi escapulida. (Lílian, 29 anos, área urbana)

[0 primeiro filho] foi sem querer. O meu segundo filho foi planejado. Porque eu tinha a ideia: "Agora eu ganho o neném e opero. Dois tá ótimo". O terceiro foi quando nós fomos viajar, chegou lá, lá precisava de receita para comprar o remédio e eu não tinha levado. (Fernanda, 29 anos, área urbana)

Por fim, a relação entre produção e reprodução para as mulheres nos estágios mais avançados de evolução da fronteira parece ser ainda mais fraca do que para o outro perfil de entrevistadas. Se antes as dificuldades na nova terra faziam com que as mulheres quisessem menos filhos, atualmente, o trabalho na terra já não demanda tanta mão de obra familiar nem desperta interesse nas gerações mais novas. Nesse sentido, nem é levado em conta ao definir as preferências e estratégias reprodutivas.

A pessoa, muitas vezes, prefere sair para trabalhar fora do que trabalhar para a família. Se você trabalhar, o seu pai não vai pagar. Então, a maioria das pessoas hoje em dia prefere trabalhar fora. Muitas pessoas do sítio vem para a cidade, trabalhar em supermercado, serraria. Compensa mais do que trabalhar na terra. Você pensa, trabalhar no sol quente o tempo todo. (Fernanda, 29 anos, área urbana)

Hoje em dia a gente não quer ter filhos para... "Ah, eu quero ter filhos para me ajudar no pasto, ajudar na lavoura, na colheita, no café". Eu quero ter filho para ele ser alguém, para ele ser um médico, para ele ser um dentista, um advogado. (Clara, 25 anos, área rural)

[Entrevistadora: Se você tivesse um lote seu e do seu marido, você gostaria de ter mais filhos pra ajudar?] Não. Continuaria nesses dois. (Suzana, 25 anos, área rural)

Para essa geração de mulheres na fronteira, as estratégias reprodutivas passam não mais por restrições econômicas das condições iniciais da fronteira, mas sim pelas novas condições ofertadas. A ampliação da comunicação, urbanização e oferta de serviços (incluindo de SSR) possibilita pensar alternativas além de só casamento e filhos, desenhando um ideal de poucos filhos e permitindo de maneira mais efetiva sua concretização - ainda que, algumas vezes, a realidade restrinja alcançar os planos ou efetivar o ideal de filhos.

\section{Discussão e considerações finais}

Este artigo investigou as estratégias reprodutivas de duas coortes de mulheres em distintas fases de desenvolvimento de uma região de fronteira agrícola. Conquanto a literatura indique uma série de teorias e fatores determinantes da fecundidade nessa região, as entrevistas parecem não corroborar totalmente as proposições de uma única teoria. Em particular, as mulheres dos dois grupos entrevistados não explicitaram ter tido filhos para 
ajudar na terra, seja por fatores relacionados à oferta de terras, de mão de obra domiciliar ou de segurança fundiária.

Portanto, para as entrevistadas, não haveria uma relação direta entre uso da terra e número de filhos. Além disso, elas não acreditam que as gerações de suas mães e avós tenham elevado sua fecundidade com essa intenção. Os resultados deste artigo convergem com as críticas a essas hipóteses (CLAY; JOHNSON, 1992; CARR, 2004), que apontam que a relação entre produção e reprodução seria, na realidade, espúria. Assim, a disponibilidade de serviços, o uso de contraceptivos, a duração do casamento, os valores e tradições culturais intermediariam essa relação.

Pelos resultados, esses fatores teriam, sim, grande relevância no contexto em análise. A necessidade de trabalho na terra para subsistência, mais do que estimular (como propõe a land-labor demand hypothesis), parece inibir a fecundidade. Ainda que as mulheres não enxerguem uma relação direta entre filhos e terra, as condições iniciais do lote e do plantio e o trabalho fora da própria terra dispensavam a ajuda dos filhos. Também não foram encontrados elementos que se relacionassem à land-security hypothesis e à reverse hypothesis.

A estratégia de analisar diferentes coortes de mulheres (e, consequentemente, diferentes ciclos de exposição ao ambiente de fronteira) permite supor que a associação entre reprodução e uso da terra possivelmente tenha sido mais forte em um passado mais distante e em contextos diferenciados, principalmente mais ruralizados e dependentes unicamente da mão de obra familiar, como os estudados por Caldwell (1982), e diferentes do cenário da fronteira amazônica. Em contextos mais recentes, em que a fronteira deixa de ser predominantemente agrária, a relação entre reprodução e uso da terra se torna ainda mais enfraquecida, como encontrado para a Amazônia equatoriana em Barbieri et al. (2005).

Os resultados sugerem que as estratégias reprodutivas e contraceptivas estariam mais relacionadas às condições materiais individuais, de infraestrutura (especialmente de SSR) e de sobrevivência na fronteira, corroborando Pan e Carr (2002, 2006, 2016). Os autores também encontram associação entre fatores socioeconômicos e de infraestrutura de SSR e decisões reprodutivas na Amazônia equatoriana. Todavia, embora no estudo de 2016 seja registrada, nos anos 1990, relação entre fecundidade e tipo de uso da terra, os autores ressaltam que outros fatores podem estar atuando na fecundidade contemporânea.

A household life cicle apresenta mais aderência ao contexto observado, no sentido de filhos muito pequenos não colaborarem tanto no trabalho na terra, aumentando a pressão sobre o domicílio. Já a saída dos filhos adultos e o envelhecimento dos pais induzem à mudança para a pecuária. Há, nesse sentido, alguma referência ao tempo na fronteira, nivel de fecundidade e estratégia de uso da terra. Tais escolhas, entretanto, podem refletir outros fatores contextuais e espúrios, conforme sugerido por Barbieri et al. (2005) e Pan e Carr (2002, 2006, 2016), e não necessariamente fatores relacionados à composição demográfica e aos ciclos de vida domiciliares.

De fato, os resultados deste artigo não sugerem uma relação inequívoca entre estratégias reprodutivas e tipo de uso da terra, inclusive da mudança para pecuária, para nenhuma 
das gerações. A rigor, são as próprias especificidades da fronteira brasileira, no que se refere ao perfil do migrante e sua vivência na não fronteira, à forte articulação urbano-rural e, ainda, às suas condições naturais e estruturais de serviços e uso da terra, que tiveram grande influência especialmente entre as mulheres pioneiras da fronteira, semelhante ao encontrado por Sydenstricker (1990).

Os achados apontam, ainda, uma preferência, comum às duas coortes, por poucos filhos, mas com motivações subjacentes a essa preferência distintas. Enquanto para a geração pioneira as difíceis condições socioeconômicas da família e a infraestrutura do PA influenciaram esse desejo, entre as mais novas, o ideal por menos filhos relaciona-se aos planos pessoais e às dificuldades materiais de criação de um filho, com menor peso das condições estruturais da fronteira. As próprias entrevistadas notam diferenças nos projetos de vida, com ambos os grupos percebendo a geração mais velha com menos possibilidades de estudar e trabalhar do que a geração mais nova. Por conseguinte, as estratégias para alcançar essas preferências também são distintas entre as coortes. Em geral, os companheiros pouco opinam sobre número de filhos e métodos contraceptivos, mostrando relações assimétricas de gênero. Desse modo, é responsabilidade da mulher decidir e traçar suas próprias estratégias reprodutivas mediante seu contexto.

A falta de acesso aos serviços de SSR e de conhecimento sobre espaçar os nascimentos e uso correto de métodos, juntamente com as parcas condições materiais, determinou que as pioneiras tivessem mais filhos do que o desejado, ou antes do momento considerado oportuno. Desse modo, a única (ou pelo menos a mais tangível) estratégia para não ter mais filhos foi a esterilização.

Entre as mulheres das fases mais atuais, a melhora nas condições de infraestrutura e serviços e o maior acesso à informação permitem práticas contraceptivas mais variadas e efetivas. Todavia, nem sempre implementam com sucesso suas preferências reprodutivas e ideacionais, pois a falta de oportunidades profissionais e educacionais em Machadinho faz com que, muitas vezes, a união e os filhos sejam vistos como o único caminho para uma vida nova.

Outro ponto relevante nas duas coortes é a forte tendência pela terminação da fecundidade por meio da laqueadura, coerente com a elevada prevalência desse método na região Norte, onde está arraigada uma “cultura da laqueadura” (BERQUÓ, 1993; FAÚNDES, 2001). Mesmo entre as mais novas, que possuem mais sucesso em espaçar os nascimentos, esse método é bastante difundido. A opção por um método definitivo pode indicar que há, para todas, em escala diferenciada, uma dificuldade em acessar alternativas de serviços de SSR.

Por fim, conclui-se que, se entre as mulheres que chegaram no início da fronteira já não há fortes evidências de relação entre terra e número de filhos, para as mais jovens ela é quase inexistente. De fato, as inovações trazidas pelo desenvolvimento econômico, urbanização e escolaridade mudam a percepção das mulheres sobre seu futuro e impactam nas suas escolhas reprodutivas. Porém, a urbanização inacabada e os problemas de 
infraestrutura fazem com as estratégias utilizadas acabem se diferenciando devido às possibilidades e limitações existentes em cada momento e ao peso distinto que fatores como acesso à terra, necessidade de mão de obra, qualidade dos serviços de SSR e expectativas individuais assumem em cada etapa da fronteira.

\section{Referências}

ALVES, J. E. D.; CORREA, S. Igualdade e desigualdade de gênero no Brasil: um panorama preliminar, 15 anos depois do Cairo. In: ABEP; UNFPA. Brasil, 15 anos após a Conferência do Cairo. Campinas: Abep/UNFPA, 2009. p. 121-223.

BARBIERI, A. F.; BILSBORROW, R. E.; PAN, W. Farm household lifecycles and land use in the Ecuadorian Amazon. Population and Environment, v. 27, n. 1, p. 1-27, 2005.

BARBIERI, A. F.; SANTOS, R. O.; GUEDES, G. R. The migration, environment and development nexus in the frontier: a review of the literature based on empirical evidences from the Brazilian Amazon. In: DETERMINANTS OF INTERNATIONAL MIGRATION CONFERENCE. Proceedings [...]. Oxford: Demig, 2014.

BARBIERI, A. F.; GUEDES, G. R.; SANTOS, R. O.; FONSECA, D. Deforestation from below: how can farm household demographic dynamics explain long term land use changes in the Amazon? In: MEETING OF THE POPULATION ASSOCIATION OF AMERICA. Proceedings [...]. Washington: PAA, 2016.

BARROS, J. V. S. Estratégias reprodutivas e evolução da fronteira agrícola: um estudo qualitativo para Machadinho d'Oeste, Rondônia. Tese (Doutorado) - Centro de Desenvolvimento e Planejamento Regional, Universidade Federal de Minas Gerais (UFMG), Belo Horizonte, 2017.

BARROS, J. V. S.; WONG, L. R.; BARBIERI, A. F. Comportamiento reproductivo y anticonceptivo de dos cohortes de mujeres de una región de frontera agrícola en la Amazonia brasileña. Notas de Población, v. 47, n. 111, p. 189-216, 2021.

BECKER, B. K. Geopolítica da Amazônia. Estudos Avançados, v. 19, n. 53, p. 71-86, 2005.

BERQUÓ, E. Brasil, um caso exemplar - anticoncepção e partos cirúrgicos - à espera de uma ação exemplar. Estudos Feministas, v. 1, n. 2, 1993.

BERQUÓ, E.; CAVENAGHI, S. Increasing adolescent and youth fertility in Brazil: a new trend or a one-time event? In: ANNUAL MEETING OF THE POPULATION ASSOCIATION OF AMERICA. Proceedings [...]. Philadelphia: PAA, 2005.

BROWDER, J. O.; PEDLOWSKI, M. A.; WALKER, R. Revisiting theories of frontier expansion in the Brazilian Amazon: a survey of the colonist farming population in Rondônia's post-frontier, 19922002. World Development, v. 36, n. 8, p. 1469-1492, 2008.

CALDWELL, J. C. Theory of fertility decline. London: Academic Press, 1982.

CARR, D. Proximate population factors and deforestation in tropical agricultural frontiers. Population and Environment, v. 25, n. 6, 2004.

CARR, D.; PAN, W. Fertility determinants on the frontier: longitudinal evidence from the Ecuadorian Amazon. In: ASSOCIATION OF AMERICAN GEOGRAPHERS ANNUAL MEETING. Proceedings [...]. Los Angeles, 2002. 
CARR, D.; PAN, W.; BILSBORROW, R. E. Declining fertility on the frontier: the Ecuadorian Amazon. Population and Environment, v. 1, n. 28, p. 17-39, 2006.

CARVALHO, A. A.; WONG, L. L. R. Quando e quantos filhos ter? Lições a partir de um estudo qualitativo entre casais de baixa escolaridade em Machadinho d'Oeste (RO). Gênero na Amazônia, Belém, n. 15, jan./jun. 2019.

CAVENAGHI, S. Fecundidade de jovens e acesso à saúde sexual e reprodutiva no Brasil: desigualdades territoriais. In: BRUNO, M. (org.). População, espaço e sustentabilidade contribuições para o desenvolvimento do Brasil. Rio de Janeiro: Ence, 2015. p. 231-274.

CHACHAM, A. S.; MAIA, M. B.; CAMARGO, M. B. Autonomia, gênero e gravidez na adolescência: uma análise comparativa da experiência de adolescentes e mulheres jovens provenientes de camadas médias e populares em Belo Horizonte. Revista Brasileira de Estudos de População, v. 29, n. 2, p. 389-407, jul./dez. 2012.

CEPAL. Población y salud en América Latina y el Caribe: retos pendientes y nuevos desafíos. Santiago del Chile: Cepal; Naciones Unidas, 2010.

CLAY, D.; JOHNSON, N. Size of farm or size of family: which comes first? Population Studies, v. 46, n. 3, p. 491-505, 1992.

DINIZ, A. M. A. Mobilidade e a evolução da fronteira agrícola. In: XIII Encontro Nacional de Estudos Populacionais. Anais [...]. Ouro Preto: Abep, 2002.

FAÚNDES, A. Planejamento familiar no Brasil. Febrasgo, v. 8, n. 3, p. 4-5, 2001.

GONÇALVES, G. Q.; CARVALHO, J. A. M.; WONG, L. R.; TURRA, C. M. A transição da fecundidade no Brasil ao longo do século XX - uma perspectiva regional. Revista Brasileira de Estudos de População, v. 36, e0098, 2019.

HENKEL, R. The move to the Oriente: colonization and environmental impact. In: TEMPE, L.; JERRY, R. (ed.). Modern day Bolivia: legacy of the revolution and prospects for the future. Tempe, AZ: Arizona State University, Center for Latin American Studies, 1982.

HENRIQUES, M. H. A política de colonização dirigida no Brasil: um estudo de caso, Rondônia. Revista Brasileira de Geografia, v. 47, n. 3/4, p. 317-356, jul./dez. 1984.

LAGO, T.; LIMA, L. Assistência à gestação, ao parto e ao puerpério: diferenciais regionais e desigualdades socioeconômicas. In: BRASIL. Ministério da Saúde; CEBRAP (org.). PNDS 2006: dimensões do processo reprodutivo e da saúde da criança. Brasília, 2009. p. 151-170.

MCDONALD, P. Societal foundations for explaining fertility: gender equity. Demographic Research, v. 28, n. 34, p. 981-994, 2013.

MERRICK, T. W. Fertility and land availability in rural Brazil. Demography, v. 15, n. 3, p. 321-336, 1978.

MONTE-MÓR, R. L. Espaço e planejamento urbano: considerações sobre o caso de Rondônia. Dissertação (Mestrado) - Universidade Federal do Rio de Janeiro (UFRJ), Rio de Janeiro, 1979.

MONTE-MÓR, R. L. O que é o urbano, no mundo contemporâneo. Belo Horizonte: UFMG/Cedeplar, 2005. (Texto para Discussão, n. 281).

NOGUEIRA, I. L.; CARVALHO, S. M.; TOCANTINS, F. R.; FREIRE, M. A. Participação do homem no planejamento reprodutivo: revisão integrativa. Revista de Pesquisa: Cuidado é Fundamental, v. 10, n. 1, 242-247, 2018. 
PAN, W.; RAMACHANDRAN, D.; CARR, D. Shifts in determinants of fertility among women living in the Amazon. Extended abstract. In: ANNUAL MEETING OF THE POPULATION ASSOCIATION OF AMERICA. Proceedings [...]. Detroit: PAA, 2009.

PAN, W.; CARR, D. L. Land use as a mediating factor of fertility in the Amazon. Population and Environment, v. 38, n. 1, p. 21-46, 2016.

SAWYER, D. R. Fluxo e refluxo da fronteira agrícola no Brasil: ensaio de interpretação estrutural e espacial. In: SEMINÁRIO DE POLÍTICAS AGRÍCOLAS E EXPERIÊNCIAS EM PROJETOS DE DESENVOLVIMENTO RURAL NA AMAZÔNIA. Anais [...]. Manaus: Centro de Desenvolvimento, Pesquisa e Tecnologia do Estado do Amazonas, 1983.

SUMMERS, P. M. The post-frontier: land use and social change in the Brazilian Amazon (19922002). Tese (Doutorado) - Environmental Design and Planning, Virginia Polytechnic Institute and State University, Blacksburg, 2008.

SUTHERLAND, E. G.; CARR, D.; CURTIS, S. L. Fertility and the environment in a natural resource dependent economy: evidence from Petén, Guatemala. Población y Salud en Mesoamérica Revista electrónica, v. 2, n. 1, art. 2, p.1-14, 2004.

SYDENSTRICKER, J. M. Família, fecundidade e as estratégias de assentamento em Rondônia: um estudo de caso. Campinas: Nepo/Unicamp, 1990 (Textos Nepo, n. 18).

SYDENSTRICKER, J. M. Parceleiros de Machadinho - História migratória e as interações entre a dinâmica demográfica e o ciclo agrícola em Rondônia. Dissertação (Mestrado) - Instituto de Filosofia e Ciências Humanas, Universidade Estadual de Campinas (Unicamp), Campinas, 1992.

SZABO, S. et al. Population dynamics in the context of environmental vulnerability: comparison of the Mekong, Ganges-Brahmaputra and Amazon Delta regions. ESRC Centre for Population Change, 2016. (Working Paper, 74).

TAVARES, L. S.; LEITE, I. C.; TELLES, F. S. Necessidade insatisfeita por métodos anticoncepcionais no Brasil. Revista Brasileira de Epidemiologia, v. 10, n. 2, p. 139-48, 2007.

THAPA, K.; BILSBORROW, R. E.; MURPHY, L. Deforestation, land use, and women's agricultural activities in the Ecuadorian Amazon. World Development, v. 24, n. 8, p. 1317-1332, 1996.

TORRES, H. G. A urbanização e o migrante de origem urbana na Amazônia. In: VI ENCONTRO NACIONAL DE ESTUDOS POPULACIONAIS. Anais [...]. Olinda: Abep, v. 2, 1988.

TRINDADE, R. E.; SIQUEIRA, B. B.; DE PAULA, T. F.; FELISBINO-MENDES, M. S. Uso de contracepção e desigualdades do planejamento reprodutivo das mulheres brasileiras. Ciência Saúde Coletiva, v. 26 (supl. 2), p. 3493-3504, 2019. Disponivel em: http://www.cienciaesaudecoletiva.com.br/ artigos/uso-de-contracepcao-e-desigualdades -do-planejamento-reprodutivo-das-mulheresbrasileiras/17372?id=17372. Acesso em: 14 set. 2020.

TURCHI, L. M. A colonização dirigida no processo de expansão e ocupação da fronteira agrícola: Território Federal de Rondônia. In: II ENCONTRO NACIONAL DE ESTUDOS POPULACIONAIS. Anais [...]. Abep, 1980. Disponível em: http://www.abep.org.br/publicacoes/index.php/anais/article/ view/196. Acesso em: 20 set. 2020.

WALKER, R.; PERZ, S.; CALDAS, M.; SILVA, L. G. T. Land use and land cover change in forest frontiers: the role of household life cycles. International Regional Science Review, v. 25, n. 2, p. 169-199, 2002. 


\section{Sobre os autores}

Juliana Vasconcelos de Souza Barros é doutora em Demografia pelo Centro de Desenvolvimento e Planejamento Regional (Cedeplar) da Universidade Federal de Minas Gerais. Pesquisadora de Pós-Doutorado na mesma instituição.

Laura Lídia Rodríguez Wong é doutora em Demografia pela London School of Hygiene and Tropical Medicine. Professora titular e pesquisadora do Departamento de Demografia do Centro de Desenvolvimento e Planejamento Regional (Cedeplar) da Universidade Federal de Minas Gerais (UFMG).

Alisson Flávio Barbieri é doutor em City and Regional Planning pela University of North Carolina at Chapel Hill. Professor associado e pesquisador do Departamento de Demografia do Centro de Desenvolvimento e Planejamento Regional (Cedeplar) da Universidade Federal de Minas Gerais (UFMG).

\section{Endereço para correspondência}

Juliana Vasconcelos de Souza Barros

Centro de Desenvolvimento e Planejamento Regional

Av. Presidente Antônio Carlos, 6627, Pampulha

31270-901 - Belo Horizonte-MG, Brasil

Laura Lídia Rodríguez Wong

Centro de Desenvolvimento e Planejamento Regional

Av. Presidente Antônio Carlos, 6627, Pampulha

31270-901 - Belo Horizonte-MG, Brasil

Alisson Flávio Barbieri

Centro de Desenvolvimento e Planejamento Regional

Av. Presidente Antônio Carlos, 6627, Pampulha

31270-901 - Belo Horizonte-MG, Brasil

\section{Abstract}

Reproductive strategies and development of the Brazilian Amazon agricultural frontier: a qualitative study in Machadinho d'Oeste

We analyze the reproductive strategies of two cohorts of women whose reproductive period was experienced in different stages of the agricultural frontier evolution in the Brazilian Amazon. Reproductive strategy consists of certain reproductive and contraceptive behaviors adjusted to the possibilities and adversities offered in the context of the frontier. We evaluate changes in reproductive and contraceptive strategies throughout the development process of the agricultural frontier. The different conditions throughout the development stages offered by the frontier would trigger different reproductive strategies, thus decisions would be different for women that lived their reproductive period during initial or more advanced stages of the frontier. We carried out semi-structured interviews with 60 women in Machadinho d'Oeste, Rondônia. Despite what the literature claims, the results indicate that there is no direct relationship between land use and number of children. Rather, the reproductive behavior of each cohort is related to the infrastructure of sexual and reproductive health services and to individual and frontier 
socioeconomic conditions. Despite the differences, union and childbearing occur at young ages in either stage, with a reasonable proportion of pregnancy due to contraceptive failure as well as a high rate of female surgical sterilization.

Keywords: Fertility. Reproductive and sexual health. Agricultural frontier. Amazonia.

\section{Resumen}

Estrategias reproductivas y evolución de la frontera agrícola en la Amazonía brasileña: un estudio cualitativo en Machadinho d'Oeste

Se analizan las estrategias reproductivas de dos cohortes de mujeres que vivieron en diferentes etapas de evolución de una región de frontera agrícola en la Amazonia brasileña. Se entiende por estrategia reproductiva la adopción de ciertos comportamientos reproductivos y anticonceptivos de acuerdo a las posibilidades y adversidades del contexto de la frontera. Se busca evaluar los cambios en las mencionadas estrategias en la medida en que evoluciona una región de este tipo. Las diferentes condiciones socioeconómicas por las que pasa la frontera agrícola durante este proceso diferenciarían a las estrategias reproductivas al influir en las decisiones tomadas por las mujeres que vivieron su período reproductivo en las primeras o en las fases más avanzadas de la frontera. Se realizaron entrevistas semiestructuradas en Machadinho d'Oeste, Rondônia, a sesenta mujeres, cuyos resultados muestran - a diferencia de lo que señala la literaturaque no habría relación directa entre el uso de la tierra y el número de hijos. El comportamiento reproductivo de cada cohorte está más relacionado con la infraestructura de los servicios de salud sexual y reproductiva y con las condiciones socioeconómicas individuales y fronterizas. No obstante, para ambos grupos, la unión y la maternidad son precoces, se observan alta falla anticonceptiva y alta proporción de esterilización.

Palabras clave: Fecundidad. Salud sexual y reproductiva. Frontera agrícola. Amazonia. 